\title{
CTSA e Educação Ambiental: uma perspectiva integradora em oficinas pedagógicas
}

\section{STSE and Environmental Education: An integrating perspective in pedagogical workshop}

\author{
Everton Viesba ${ }^{1}$ \\ Natália Dias ${ }^{2}$ \\ Marilena Rosalen ${ }^{3}$
}

Resumo: O presente trabalho visa apresentar uma perspectiva integradora entre Educação Ambiental (EA) e Ciência, Tecnologia, Sociedade e Ambiente (CTSA), partindo da análise de construção, desenvolvimento e resultados de uma oficina pedagógica (OPs) aplicada para estudantes secundaristas e universitários, acredita-se que a aplicação de OPs, que integrem EA e CTSA, e adotam o tripé sentir-pensar-agir, se torne uma maneira eficaz de construção do conhecimento, pautando-se pela ação-reflexão. Partindo desse aspecto, foi desenvolvida a OP "Construindo um Futuro". A OP proporcionou aos participantes descobrirem as potencialidades, problemáticas e soluções da comunidade escolar numa perspectiva socioambiental e integradora. Concluiu-se que OPs podem desempenhar papeis eficazes no processo de facilitação e tomada de decisão; favorecendo a construção coletiva do conhecimento, criando condições para que sejam protagonistas e agentes de transformação.

Palavras-Chave: Oficinas Pedagógicas. CTSA. Educação Ambiental.

Abstract: The present work aims to present an integrative perspective between

\footnotetext{
${ }^{1}$ Professor. Especialista em Educação Ambiental, Sustentabilidade e Educação a Distância. Mestre em Ciências. Coordenador do Observatório de Educação e Sustentabilidade da UNIFESP. Integrante do grupo de pesquisa Movimentos Docentes. E-mail: eviesba@gmail.com

${ }^{2}$ Mestra em Ensino de Ciências e Matemática (UNIFESP). Graduada em Ciências - Biologia pela UNIFESP. Email: natalia.fdias@outlook.com

3 Doutora em Educação. Professora adjunto do Programa de Pós-Graduação em Ensino de Ciências e Matemática da UNIFESP e coordenadora do grupo de pesquisa Movimentos Docentes. E-mail: marilena.rosalen@gmail.com
}

Recebido em 23/01/2022

Aprovado em 10/02/2022

Sistema de Avaliação: Double Blind Review 
Environmental Education (EE) and Science, Technology, Society and Environment (STSE), based on the analysis of construction, development and results of a pedagogical workshop (PWs) applied to secondary and university students, it is assumed that the application of PW, which integrate EE and STSE, and adopt the trip-feel-think-act, becomes an effective way of building knowledge, based on action-reflection. From this aspect, the "Building a Future". The PW gave the participants the potentialities, problems and solutions in their environment from a socio-environmental and integrating perspective. It was concluded that PWs can play effective roles in the facilitation and decision-making process; favoring the collective construction of knowledge, creating conditions for them to be protagonists and agents of transformation.

Keywords: Pedagogical Workshops. STSE. Environmental Education.

\section{Introdução}

Nos últimos anos, temos observado que o mundo vem sofrendo constantes mudanças culturais, econômicas, políticas e socioambientais pelo crescente avanço das Ciências e Tecnologia. A revolução tecnológica acarretou mudanças nos padrões culturais e sociais, uma vez que as tecnologias e processos da ciência tornaram-se parte do cotidiano e da vida das pessoas, fazendo com que o ser humano adapte-se e aprenda a lidar com as novas tecnologias e com os avanços da ciência, como uma ferramenta que facilita a sua vida. Segundo Bazzo (1998, p. 142):

\footnotetext{
É inegável a contribuição que a ciência e a tecnologia trouxeram nos últimos anos. Porém, apesar desta constatação, não podemos confiar excessivamente nelas, tornando-nos cegos pelo conforto que nos proporcionam cotidianamente seus aparatos e dispositivos técnicos. Isso pode resultar perigoso porque, nesta anestesia que o deslumbramento da modernidade tecnológica nos oferece, podemos nos esquecer de que a ciência e a tecnologia incorporam questões sociais, éticas e políticas.
}

Para Pinheiro, Silveira e Bazzo (2007), é necessário que a população tenha acesso às informações sobre o desenvolvimento científico-tecnológico, mas também tenha condições de avaliar e participar das decisões que venham a gerar impactos para o meio em que vivem, ou seja, desenvolvam uma conduta cidadã. Os autores ainda exploram que é necessário que a sociedade, em geral, comece a questionar sobre os impactos da evolução e aplicação da ciência e tecnologia sobre seu entorno e consiga perceber que, muitas vezes, certas atitudes não atendem à maioria, mas, sim, aos interesses dominantes. Bazzo (1998, p.114), amplia esta ideia: 
O acervo de conhecimentos científicos e tecnológicos não se constitui de maneira linear, contínua e sucessiva. Entretanto, os resultados do conhecimento científico e tecnológico circulam e produzem efeito no mundo contemporâneo de modo sem precedentes. É cada vez maior a influência da ciência e da tecnologia em nossas vidas, e as inovações chegam ao nosso dia a dia com muita rapidez. Contudo, é fundamental que se priorize o debate de questões que envolvam a dimensão social da ciência e da tecnologia. Se tais avanços podem trazer melhorias, por outro lado demandam reflexões sobre sua relação com valores éticos.

Para que questões da Ciência - de relevância social - sejam compreendidas, torna-se necessário que as pessoas tenham acesso ao conhecimento científico, de maneira a efetivar o princípio da participação e do exercício da cidadania. Afinal, em uma sociedade democrática é fundamental que o cidadão tenha condições de participar tanto das decisões que dizem respeito a seus interesses individuais como daquelas que afetam toda a comunidade.

Espera-se que a escola, possa, em conjunto com diversos outros grupos e agentes sociais - como os meios de comunicação e os espaços não formais de divulgação científica -, promover o acesso ao conhecimento científico com criticidade, qualificando indivíduos para a leitura e o entendimento do mundo. Nesse contexto cabe ao Ensino de Ciências (EC) constituir-se numa ferramenta para despertar no estudante essa atitude crítica, estimulando-o a questionar respostas fortuitas ou soluções falaciosas.

O desafio é incorporar à prática de ensino, os conhecimentos de Ciências e Tecnologia relevantes para a formação de atitudes cidadãs. Para tanto, o EC, além do compromisso com as informações e com a técnica competente, deve se basear em valores comprometidos com a responsabilidade social e com os princípios éticos de respeito a todos os seres vivos, e com o ambiente.

Tais questões e fenômenos político-sociais levam a uma grande mudança no modo de agir e pensar, acarretando uma revolução cultural que interfere também no campo educacional. Assim, existem sinais da emergência de novas formas de pensar, de agir e de viver a realidade que tem implicações na escola e refletem-se na forma de conceber a formação e o currículo.

Segundo Bachelard (1996), pensar o EC em íntima conexão com o cotidiano não significa ficarmos no nível do senso comum. O senso comum há que ser explicitado, problematizado e retificado. Estes podem ainda, serem aspectos possivelmente configuradores de novas práticas pedagógicas e de novos desafios práticos para os professores, principalmente entre os adolescentes e jovens. Surge a possibilidade de se trabalhar temas transversais no âmbito escolar como Ciência, Tecnologia, Sociedade e Ambiente (CTSA). 
A CTSA é uma área que contribui para o desenvolvimento integral da pessoa, em relação com a natureza da qual faz parte, com a tecnologia e com o seu ambiente, no âmbito de uma cultura científica. Tem como objetivo fornecer soluções alternativas para os problemas socioambientais e de saúde na tentativa de alcançar uma melhor qualidade de vida.

\section{Ciência, Tecnologia, Sociedade e Ambiente}

A área de CTSA desenvolve o pensamento científico para compreender e aplicar Ciência e Tecnologia para beneficiar a humanidade. Tecnologia é todo aquele instrumento humano que facilita suas atividades e suas necessidades. A Real Academia Espanhola (2016, n.p. tradução nossa), define tecnologia como: "Conjunto de teorias e técnicas que permitem o aproveitamento prático do conhecimento científico". A origem etimológica da palavra tecnologia, nos ajuda a entender melhor seu significado. Uma palavra proveniente do grego tekné, que significa: arte, técnica, ou ofício, e ciência como conhecimento, um tratado científico. A sua raiz, está estreitamente ligada da sua distinção com a técnica. Segundo Vargas (2011) a tecnologia não é uma mercadoria que se compra e se vende em qualquer instante, quando se quer, é na verdade, um saber que se adquire pela educação teórica e prática, e, principalmente, pela pesquisa tecnológica, por meio de uma técnica, a qual é definida pelos conhecimentos e procedimentos práticos, com enfoque a produzir um resultado determinado, de maneira consistente.

Definindo sucintamente o termo Ciências, podemos considerá-la como um conhecimento sistematizado, desenvolvido por meio de observações, argumentos e provas metodicamente organizado. A ciência utiliza diferentes métodos e técnicas para a aquisição e organização do conhecimento sobre a estrutura de um conjunto de objetivos e acessíveis a vários observadores, bem como sendo baseado em um critério de uma metodologia científica, que não é único, mas deve ter um rigor. A aplicação destes métodos e conhecimentos leva à geração de conhecimento mais objetivo na forma concreta, quantitativa e predições testáveis sobre fatos observáveis passados, presentes e futuros. A ciência é igual a qualquer outra atividade humana: não é totalmente objetiva. Ela se desenvolve a partir de uma mescla de misticismos, e observações objetivas. Segundo Perrenoud (2000) no período do Renascimento, e especificadamente com as obras do Galileu e seus contemporâneos, a ciência começou a desenvolver sua natureza especializada, de forma a ser cada vez mais 
compreensível para quem está distante do mundo científico.

Trabalhar com CTSA é permear - em termos de conceitos, teorias e práticas - a Ciência e a Tecnologia com intuito de desenvolver habilidades e atitudes científicas para permitir que o sujeito participe ativamente na sociedade e não fique à margem do conhecimento científico, desenvolvendo capacidades científicas que lhe permitam desenvolver o pensamento crítico em relação às questões socioambientais. Sendo estes parâmetros marcos do desenvolvimento de uma cultura científica, pois desenvolve atitudes e capacidades científica-críticas que permitem a inserção dos sujeitos na sociedade do conhecimento e contribuem para a melhora da qualidade de vida no contexto de uma cultura científica-tecnológica. Com relação ao EC, os conhecimentos na área, podem ser divididos em: a) Conhecimento do Mundo, Tecnologia e Meio Ambiente; b) mundo Físico, Tecnologia e Meio Ambiente; c) Saúde Integral, Tecnologia e Meio Ambiente. E da interação dessas subáreas surge uma grande área que é a Interação da Ciência, Tecnologia e Ambiente, conforme figura 1, que estão imersas em um contexto e ações sociais. Levando os educandos à capacidade de compreensão para analisar os fatos, conceitos, princípios científicos e tecnológicos e para internalizar vários processos biológicos, químicos e físicos que ocorrem na natureza, através da investigação e experimentação.

Figura 1. Subáreas do Ensino de Ciências Naturais resultando na Interação CTA.

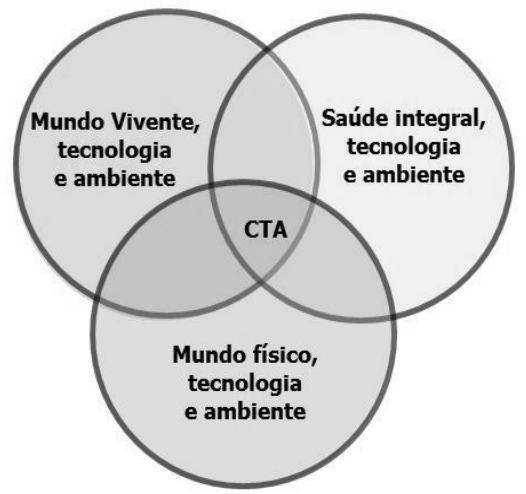

Fonte: Desenvolvido pelos autores.

A investigação e a experimentação são necessárias, pois contribuem para o desenvolvimento do pensamento sistêmico e o levantamento de soluções razoáveis para um problema. Assim, o desenvolvimento do pensamento na abordagem de CTSA é importante para compreender e agir no mundo. Compreender o ambiente natural e a diversidade, o desenvolvimento da consciência orientada para gestão de risco ambiental e uso racional dos 
recursos naturais no quadro de uma cidadania na sociedade pós-moderna. A ação pedagógica dentro desta área contribui para o desenvolvimento do pensamento sistêmico, que levanta soluções razoáveis para um problema social, tecnológico, político e ambiental. É importante que o professor compreenda a investigação crítica e pensamento criativo, como um meio de aprender.

É necessário selecionar estratégias didáticas atendendo o enfoque da indagação com relação à conservação ambiental do mundo físico e organização do mundo vivente. Com isso trabalha-se CTSA com enfoque na indagação e sensibilização. Assim é necessário promover atividades que estimulem a formação de questionamentos e levantamento de hipóteses de princípios gerais, criando competências para o desenvolvimento do pensamento críticocientífico. Segundo Gunstone e Northfie (1994) estas atividades têm um forte caráter metacognitivo na medida em que, se desenvolvem corretamente, ajudando os estudantes a aprender a ser consciente de seus próprios processos cognitivos.

Elencamos algumas estratégias de ensino que podem ser utilizadas como ferramentas para ações de EA: trabalhos de pesquisa; trabalhos de campo; uso de laboratórios para testes e experimentações; projetos e simulações; uso de Tecnologias da Informação e Comunicação (TIC); aprendizagem baseada em problemas; técnicas de investigação; leitura de teorias e princípios com diversos propósitos e oficinas pedagógicas, essa última é o foco de estudo e relato deste trabalho.

\section{Meio Ambiente, Educação Ambiental e Escolas Sustentáveis}

A crise socioambiental que surgiu nas últimas décadas, tem se intensificado ano após ano, os avanços da Ciência e Tecnologia muitas vezes são tomados pelo ser humano como uma forma de manter posição na "hierarquia da natureza", se sobressaindo em relação ao meio ambiente e fazendo uso de seus recursos sem um planejamento e manejo adequados, favorecendo sua degradação, prejudicando suas capacidades de resiliência e promovendo o distanciamento entre ser humano e meio ambiente.

Com a crise socioambiental que a humanidade está enfrentando, de proporções únicas, a EA tem emergido como uma das chaves na busca pela garantia de futuro da humanidade e da sustentabilidade de suas ações, principalmente no contexto educacional. Quando se pensa em futuro da humanidade é impossível dissociar educação da sustentabilidade e a Declaração 
de Dakar (UNESCO, 2001, p. 6) afirma isso em seu objetivo 6, tratando a educação como uma "chave para um desenvolvimento sustentável, assim como para assegurar a paz e a estabilidade dentro e entre países...”. Mais recente, a Declaração de Bonn (UNESCO, 2014, p. 2), estabelece a Educação para a Sustentabilidade como "um novo direcionamento no ensino e na aprendizagem" que se baseia em "valores de justiça, retidão, tolerância, autonomia e responsabilidade" com importantes princípios que nos levem "a modos de vida sustentáveis".

Contudo, a EA ainda é considerada uma temática nova e mais nova ainda é a perspectiva Educação para a Sustentabilidade. De tal modo, assim como diversas outras temáticas e ciências novas, a EA é compreendida de forma equivocada por muitos, principalmente professores. Tratada como especialidade, disciplina ou eixo transversal quase invisível em comparação a outras temáticas, grande parte das ações de EA não favorecem a criticidade, são planejadas e desenvolvidas como ações pontuais e não promovem a reflexãoação dos temas trabalhados. Baseiam-se em ações informativas, mecanicistas, sem uma reflexão prévia de suas premissas, sem clareza de suas bases político-pedagógicas. Isso é facilmente percebido em ações de EA sobre coleta seletiva e resíduos sólidos em escolas, costuma-se premiar as turmas que mais trouxerem resíduos potencialmente recicláveis para a escola, atitude que incentiva o consumismo nos estudantes, que na busca pelo prêmio, pela satisfação em competir e ganhar consomem mais produtos para gerar mais resíduos recicláveis, isto pode ser considerado como uma pedagogia da reciclagem, onde o resíduo é um problema, e neste caso, a EA nada mais é do que um instrumento técnico da gestão ambiental.

Embora seja uma área relativamente nova, são vários os conceitos sobre o que é EA e várias as correntes que a permeiam, entre as mais tradicionais, se encontram: a corrente naturalista, corrente conservacionista, corrente humanista e corrente moral/ética; contudo já existem correntes mais recentes, como: corrente holística, corrente práxica, corrente crítica e a corrente da sustentabilidade (SAUVÉ, 2005). Os conceitos mais amplos costumam se complementar, para fins de atuação direta considera-se como referência principal a Política Nacional de Educação Ambiental (BRASIL, 1999) instituída pela Lei 9.795/99, onde se entende por EA:

Os processos por meio dos quais o indivíduo e a coletividade constroem valores sociais, conhecimentos, habilidades, atitudes e competências voltadas para a 
conservação do meio ambiente, bem de uso comum do povo, essencial à sadia qualidade de vida e sua sustentabilidade.

Em complemento, as Diretrizes Curriculares Nacionais para a Educação Ambiental (BRASIL, 2012), consideram em seu artigo $2^{\circ}$ que a EA é uma importante área da educação sendo uma "atividade intencional da prática social, que deve imprimir ao desenvolvimento individual um caráter social em sua relação com a natureza e com os outros seres...”. A EA é um processo que possibilita despertar a preocupação e o estímulo à responsabilidade individual e coletiva para as questões socioambientais, contribuindo com o desenvolvimento de uma consciência crítica, com ações e reflexões emancipatórias, favorecendo um trilhar para transformações culturais, políticas, econômicas, sociais e ambientais, tornando os sujeitos os protagonistas das suas transformações individuais e agentes de transformações coletivas.

Desta forma, a partir de diversos projetos de EA desenvolvidos no município de Diadema, São Paulo, por meio do Programa Institucional de Bolsas de Iniciação à Docência (PIBID) desde 2012, foi construído o Programa Escolas Sustentáveis. Trata-se de um programa de extensão que tem como principal objetivo implementar práticas sustentáveis em comunidades escolares da Região Metropolitana de São Paulo, promovendo e contribuindo com as ações de EA existentes, visando fomentar a reflexão-participação-ação dos membros da comunidade escolar na construção de um espaço educador ecologicamente correto, economicamente viável e social e culturalmente justo.

As ações de EA do Programa tem um diferencial por trabalhar a pedagogia dos 5 R's (Repensar, Recusar, Reduzir, Reutilizar e Reciclar), tendo o consumo como problema, além da questão ética e moral de reaproximação Ser Humano - Natureza, trazendo a EA enquanto um importante campo de transformação da realidade, sensibilização e conscientização, fomentando a reflexão-ação dos sujeitos e favorecendo a promoção de agentes transformadores.

As ações do Programa são desenvolvidas em quatro áreas de atuação, sendo: Currículo, Espaço, Gestão e Formação. Cada área dá origem a diversos eixos que se interligam, e sua totalidade de ações visa à consolidação de um espaço educador sustentável. As Oficinas Pedagógicas desenvolvidas pelo Programa se enquadram na área Currículo e fazem conexão em eixos como Ensino; para favorecer a interdisciplinaridade são desenvolvidas por uma equipe composta por doutores, mestrandos, professores do ensino 
básico e graduandos de ciências ambientais, biológicas e licenciatura; carregam consigo o objetivo central de promover a EA de forma que os participantes não sejam meros coadjuvantes no processo, mas sim protagonistas que reconhecem suas próprias realidades e entendem a necessidade de transformação desta.

Trabalhar a EA por meio de Oficinas Pedagógicas é uma importante alternativa que se constitui como um avanço na educação básica, pois permite a criação de atividades que desenvolvem o senso crítico no participante e o leva a reflexão sobre os problemas locais e globais, desencadeando a autonomia no "agir", tornando-os protagonistas no contexto histórico atual. Díaz (2002, p. 35) confirma isso, quando afirma que:

Se pretendemos que a escola forme indivíduos com capacidade de intervenção na realidade global e complexa, teremos de adequar a educação, em seu conjunto, aos princípios do paradigma da complexidade e, por conseguinte, às características de uma aproximação sistêmica. Temos que promover uma educação que responda precisamente a essa realidade global e complexa, e que dê uma resposta adequada a seus problemas, entre eles, o da crise ambiental.

O Programa Escolas Sustentáveis não é somente uma proposta preventiva para mitigarmos ou evitarmos problemas. É um caminho de construção de sociabilidades solidárias, de relações criativas e afetivas com a natureza, da qual somos parte. São caminhos com horizontes indefinidos, mas instigante, pois é fruto de um processo coletivo e participativo, o viés extensionista do Programa contribui neste trajeto, aproximando Universidade-Escola-Comunidade e promovendo a junção da teoria-prática, bem como a reflexão-participação-ação seja de estudantes do ensino básico - costumeiramente objetos de estudo na Academia; seja de estudantes e pesquisadores universitários - que se veem numa oportunidade ímpar de viver as diferentes realidades e complexidades outrora focos de estudo. O trabalho com EA e CTSA por meio de Oficinas Pedagógicas é um importante caminho que provoca e convida a um senso de abundância, de alegria, de construção de novas realidades, da busca pelo conhecimento científico e cultural e do respeito ao meio ambiente, à sociedade e à vida. 


\section{Oficinas pedagógicas}

Harvey (1993) analisa características da pós-modernidade, e aponta que o caráter fragmentário e instável das verdades e dos discursos produzidos na sociedade (que se baseia na produção e na exploração de espetáculos e imagens da mídia que globalizam a cultura e a economia), podem nos levar a entender os efeitos dessa globalização e o modo como ela interfere no cotidiano da sociedade, sendo este um caminho para entender o cotidiano escolar.

Os reflexos dessa modificação estão presentes nas relações sociais, no modo como o ser humano interage com o ambiente, o ecossistema ao seu redor e consigo mesmo. Chiavenato (1998) considera que a globalização é um processo que age diretamente sobre o ser humano, no qual suas consequências sociais e econômicas estão transformando o modo de vida das pessoas, seus valores éticos, morais, conceitos políticos e sociais. Com isso, segundo Gadotti (2000) uma educação autêntica deve ensinar a contextualizar, concretizar e globalizar, ai está o ponto da EA, uma educação transdisciplinar que reavalia o papel da intuição, da imaginação, da sensibilidade e do corpo na construção dos conhecimentos.

Considerando que qualquer que seja a ação pedagógica, não podemos considerar que os conhecimentos dos educandos se constroem a partir do zero, e nem que este estudante tem uma "mente vazia" para determinados assuntos, pois os educandos possuem conhecimentos prévios e espontâneos, os quais, inclusive, poderão coexistir com o conhecimento científico e por isso, muitas vezes, o ensino choca-se de frente com as concepções dos aprendizes. Para construir as ações pedagógicas, especialmente sobre oficinas pedagógicas, foi necessário um aporte teórico e grandes referenciais da didática das ciências - (GIORDAN; DE VECCHI, 1987; ASTOLFI; DEVELAY, 1996; ASTOLFI, DAROT, GINSBURGER-VOGEL e TOUSSAINT, 1997; JOSHUA e DUPIN, 1993) - como indicado na obra de Perrenoud (2000). Isso, pois foi importante para aproximar os conhecimentos espontâneos dos estudantes sobre questões ambientais, por exemplo, locais e globais, com conhecimento científico e planejar as oficinas pedagógicas.

A palavra "oficina", em latim significa, figurativamente, "escola" (FARIA, 1962), as oficinas pedagógicas que supõem um contexto pedagógico ao mesmo tempo são estáveis e dinâmicas, por possibilitar a interação entre os participantes.

Vieira e Volquind (2002, p. 11) definem oficina como sendo: "uma modalidade de ação", nada mais que "um tempo e um espaço para aprendizagem; um processo ativo de 
transformação recíproca entre sujeito e objeto" perfazendo um importante caminho "com alternativas, com equilibrações que nos aproximam progressivamente do objeto a conhecer". Oficinas pedagógicas representam uma importante forma de construir o conhecimento, pautando-se principalmente pela ação-reflexão, cujo objetivo é proporcionar vivências significativas baseando-se no tripé: sentir-pensar-agir.

Necessariamente, as oficinas devem promover a investigação, ação, reflexão e possibilitar a organização de trabalhos de forma individual e coletiva, permitindo aos participantes realizarem tarefas socializadoras e garantindo a unidade entre teoria e prática. A construção de uma oficina pedagógica deve levar em conta duas finalidades: 1. Articulação de conceitos, pressupostos e noções com ações vivenciadas pelo participante; e 2. Vivência e execução de tarefas em equipe, isto é, apropriação ou construção coletiva de saberes (VIEIRA E VOLQUIND, 2002).

Paviani e Fontana (2009) concordam que a metodologia da oficina possibilita uma importante mudança no viés tradicional da aprendizagem (cognição), justamente por incorporar a ação-reflexão, permitindo a apropriação, construção e produção de conhecimentos teóricos e práticos, de forma ativa e reflexiva. Ainda de acordo com as autoras, uma oficina exige planejamento, tal qual qualquer ação pedagógica, no entanto é em seu desenvolvimento que surge a diferenciação, onde características distintas surgem, sendo necessário que os participantes se ajustem às situações-problema e busquem soluções de acordo com os contextos vivenciados. Paviani e Fontana (2009, p. 79) afirmam ainda que os procedimentos e técnicas que são utilizados são bastante variados, incluindo "a produção de materiais didáticos, a execução de materiais em sala de aula e a apresentação do produto final dos projetos, seguida de reflexão crítica e avaliação".

Com relação ao ensino-aprendizagem, as ações são articuladas com a interação entre professor e alunos e a interação entre os alunos, com troca de informações e de conhecimentos por parte dos participantes, onde o coordenador da oficina não ensina o que sabe, mas oportuniza que os participantes necessitem saber, sendo, portanto, uma abordagem centrada na interação, no envolvimento do aprendiz e na aprendizagem. A construção de saberes e as ações relacionadas decorrem, principalmente, do conhecimento prévio, das habilidades, dos interesses, das necessidades, dos valores e julgamentos dos participantes e principalmente das interações oportunizadas nas oficinas pedagógicas (PAVIANI E FONTANA, 2009). 
A transversalidade da EA e CTSA abre um importante espaço para trabalhos em oficinas pedagógicas, considerando que diversos são os temas do currículo que podem ser trabalhados a partir de ambas as perspectivas. Dessa forma, espera-se que a aplicação de oficinas pedagógicas, que integrem EA e CTSA, se torne uma maneira eficaz de construção do conhecimento, pautando-se pela ação-reflexão a partir do tripé sentir-pensar-agir.

\section{Oficina pedagógica "Construindo um Futuro"}

Ao longo dos últimos anos (2015 - 2018), a equipe do Programa Escolas Sustentáveis desenvolveu diversas oficinas pedagógicas: "Construindo um Futuro", "Nosso Consumo, nossa Pegada", "Conhecendo as Potencialidades Socioambientais de uma escola" "Problemáticas e Potencialidades Socioambientais no entorno de uma Universidade" entre outras. As oficinas foram desenvolvidas, num primeiro momento, para compor a Semana Científica e Cultural da Unifesp Diadema (SCCUD). A SCCUD é um evento anual, organizado desde 2009, por estudantes da Universidade Federal de São Paulo, campus Diadema, e tem o objetivo de oferecer atividades do ramo cultural, palestras, mesas redondas, visitas técnicas, mostras científicas e minicursos, levando o aprendizado para fora das salas de aulas, criando um aprendizado inter-relacionado, integração entre estudantes, universidades e empresas e valorizando a produção científica e cultural da região (SCCUD, 2009).

As oficinas pedagógicas completaram em 2018 seu $4^{\circ}$ ano consecutivo de participação na SCCUD e em cada ano, novos desafios aparecem, mas como Freire e Toffler afirmam em outras palavras: "A vontade de aceitar desafio é uma questão de sentido" (PERRENOUD 2000, p. 48). A participação do Programa Escolas Sustentáveis consecutivamente na SCCUD, deve-se ao fato de oferecer atividades em que educandos (estudantes secundaristas e universitários) possam falar e ouvir a respeito das realidades próprias e distantes, podendo lêlas e relê-las, por meio de suas argumentações seja em fala, gestos, expressões ou no silêncio. A intenção pedagógica das oficinas é lidar e criar saberes, em suas trocas de experiências, em suas reflexões, compondo e propondo novas questões que os levem a perceber a necessidade de estarem sempre presentes no processo dinâmico de mudanças ambientais, do equilíbrio de ecossistemas, os biótopos, e assuntos de CTS, características que contribuem na integração entre EA e CTSA.

A elaboração das oficinas ficou sob responsabilidade da equipe técnica do Programa, a 
qual realizou um levantamento na literatura de papers, planos de aula e atividades em diversas bases de dados como o portal "Periódicos Capes", com o auxilio de busca booleana utilizando palavras-chave como: oficinas, oficinas pedagógicas, dinâmicas pedagógicas e dinâmicas em sala de aula. Em seguida foi feito um recorte por papers que se relacionavam com EA, CTS, CTA, CTSA, Educação para a Sustentabilidade, Meio Ambiente e Desenvolvimento Sustentável. O levantamento de planos de aula e atividades foi realizado a partir de sites com viés educacional, entre eles: "Portal do Professor", "Currículo +", "Escola Interativa" e "Nova Escola".

Para a oficina "Construindo um Futuro", foram selecionadas duas experiências amplamente difundidas na EA, conhecidas popularmente como "Árvore dos Sonhos" e "Muro das Lamentações", após uma análise sobre as metodologias e práticas utilizadas, foi definido que seria feita uma adaptação sobre as experiências. A adaptação resultou nas dinâmicas chamadas de: "Mar de Problemas", "Árvore dos Sonhos", e "Trilha das Realizações", foram realizadas ainda duas palestras intituladas: "Meio Ambiente Urbano" (ministrada por uma representante do setor de EA da Secretaria do Meio Ambiente de Diadema); e "Escolas e Sociedades Sustentáveis" (pelo professor-coordenador do Programa Escolas Sustentáveis). Participaram desta oficina, 40 pessoas, sendo 15 universitários, 15 estudantes do ensino básico, 5 membros do Programa e 5 convidados, entre gestores e palestrantes. No decorrer da oficina, vários professores da escola participaram das atividades e interagiram com os participantes nas situações propostas. A oficina foi desenvolvida e estruturada sob a perspectiva da relação teoria-prática fundamental na educação dialógica (FREIRE, 1996). Com duração de quatro horas, a oficina partiu do questionamento "como a EA e a CTSA podem promover uma escola / sociedade sustentável?".

A primeira experiência intitulada "Mar de Problemas" provocou os participantes a identificarem as problemáticas socioambientais existentes na contemporaneidade numa escala global, de forma a abrir seus horizontes e vislumbrar a raiz de problemáticas locais. Foi criada numa parede a ilustração de um "mar" (Figura 1), simbolizando um suporte, aparentemente infinito, de problemáticas que podem ser levantadas.

Figura 1. Painel Mar de Problemas, ilustrando as problemáticas socioambientais. 


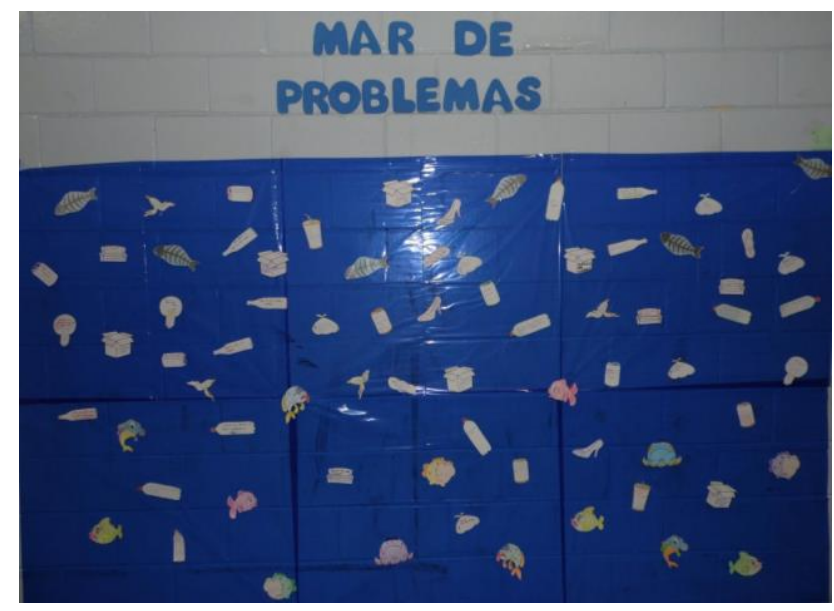

Fonte: Arquivo do Programa Escolas Sustentáveis/Proec

Para estimular os participantes foram ilustradas algumas problemáticas, como poluição por resíduos nos mares, peixes mortos e proliferação de doenças. Os participantes em grupos heterogêneos evoluíram de problemáticas locais, como a falta de infraestrutura ideal da escola em que a oficina ocorria e as condições péssimas de cuidado com as praças no entorno da comunidade. Até problemáticas globais como as complexidades na aplicação das políticas públicas municipais, estaduais e nacionais, no que se refere à proteção e conservação ambiental, as mudanças climáticas, o consumo e o desperdício.

A segunda atividade foi a "Árvore dos Sonhos", nela os participantes deveriam elencar os fatores para que se obtenha de fato, uma escola sustentável, lembrando que esse termo não incorpora apenas os limites físicos da unidade de ensino. Os participantes, de forma espontânea separaram os "sonhos" entre possíveis de serem realizados num prazo mais curto, dos que os pareciam utópicos, porém todos foram acrescidos à árvore ilustrada na figura 2.

Figura 2. Árvore dos Sonhos, material didático onde foram expostos os sonhos e utopias dos participantes da oficina. 


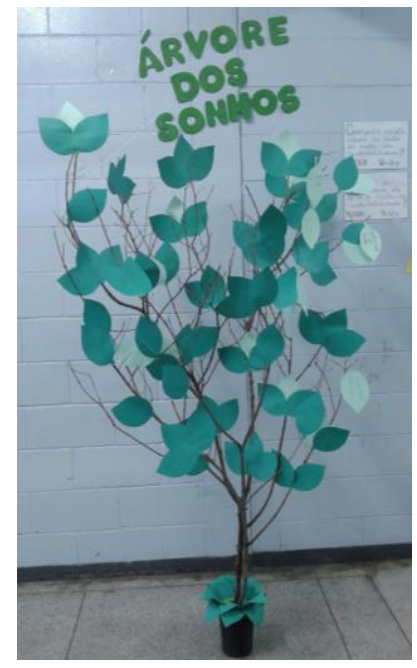

Fonte: Arquivo do Programa Escolas Sustentáveis/Proec

Identificaram-se algumas respostas importantes a nível local como: a escola sem goteiras, e com uma infraestrutura ideal, até respostas a nível global como o acesso a distribuição de água a toda a população sem escassez, o controle de doenças, a proteção aos animais, limpeza dos rios, destinação correta do lixo, aqui destacando a inexistência de lixos nas ruas; córregos, solo e queima de lixo, a ampla oferta de lazer seguro para a população e por fim o sonho de uma sociedade sustentável. A terceira atividade, "Trilha das Realizações" (figura 3) focou em provocar os participantes à reflexão sobre como as problemáticas destacadas na primeira atividade, podem ser resolvidas, de forma a atingir um ambiente como esperado nos sonhos elencados na "Árvore dos Sonhos".

Figura 3. Trilha das Realizações, atividade onde foram expostas as soluções e caminhos para a construção de espaços educadores e sociedades sustentáveis.

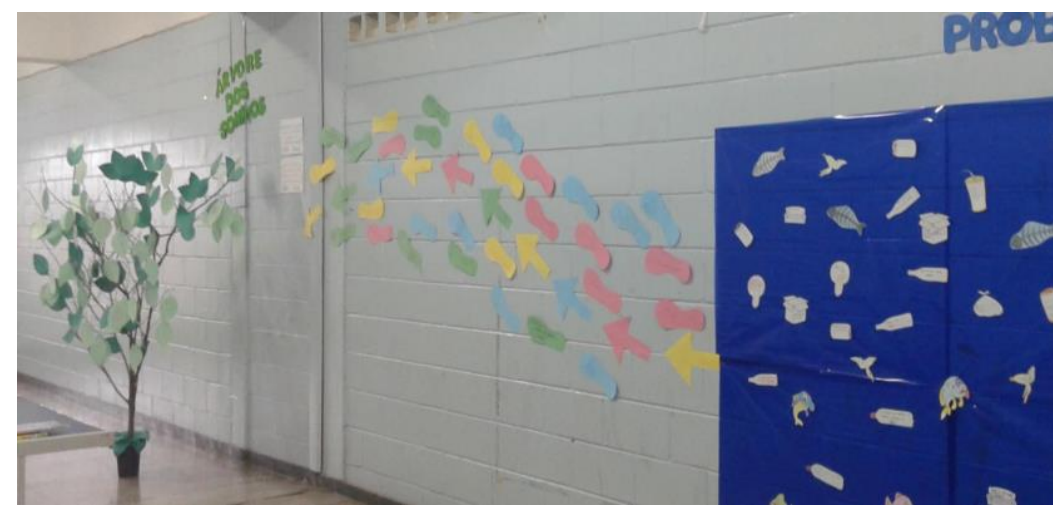

Fonte: Arquivo do Programa Escolas Sustentáveis/Proec

Essa atividade mostrou-se importante devido à resposta dos participantes envolverem princípios e propostas da CTSA, eles incorporaram à reflexão soluções conceituais e práticas, 
envolvendo a Ciência e Tecnologia para a resolução dos problemas. Exemplos dessas respostas foram: "utilização de lâmpadas mais econômicas", "construção de fábricas para tratamento e reciclagem dos resíduos gerados no município", "fontes limpas de produção de energia", "sensores de iluminação nas ruas e estabelecimentos para utilização apenas quando necessário"; outras soluções não requerem equipamentos como "reutilização de produtos", "reutilização da agua", "criação de hortas comunitárias", e destacada como a mais importante e mais ressaltada a "redução do consumo por meio da sensibilização e conscientização ambiental", resultante das ações de EA na sociedade como um todo.

O grande desafio da Oficina foi de incorporar a prática de ensino, os conhecimentos de CTSA relevantes para a formação de atitudes cidadãs, em um curto espaço de tempo, pois trabalhar com essa temática envolve além do compromisso com as informações e com a técnica, o compromisso com a responsabilidade social e com os princípios éticos de respeito a todos os seres vivos e com o ambiente.

O intuito das oficinas realizadas está em trabalhar a partir das concepções dos estudantes, dialogar, fazer com que sejam (re) avaliadas, sejam postos em reflexão sobre as questões sociais, políticas de sua cidade, país e mundo. Os educadores ambientais, que estavam em ação tinham como principal responsabilidade, orientar os estudantes e auxiliá-los a fundamentar-se em suas representações prévias, sem se fechar nelas, mas encontrando um ponto de entrada no sistema cognitivo dos estudantes, uma maneira de desestabilizá-los, para levá-los a restabelecerem o equilíbrio, incorporando novos elementos às representações existentes e reorganizando-as, se necessário.

Considerando este contexto, o Programa Escolas Sustentáveis está fundamentado no fato de que não é necessário que os educandos memorizem informações ou dados técnicos de situações ambientais, globais ou locais, mas sim se sensibilizem sobre essas informações, sobre essas situações. Se sensibilizem através de seus sistemas cognitivos, reestruturando seu sistema de compreensão do mundo. Fazendo com que, a reestruturação exerça um trabalho cognitivo no educando, e assim, restabelece-se o equilíbrio rompido, e como resultado o educando acabe lidando melhor com a realidade, realizando mudanças / transformações, mesmo que pequenas.

Com a realização de mais de 3 oficinas pedagógicas durante as edições da SCCUD, é interessante observar que as situações de aprendizagem não ocorrem ao acaso, elas dependem de uma situação geradora, que no caso foi tarefa do projeto realizado, colocando os estudantes 
frente aos problemas socioambientais identificados. Não houve dispositivo didático geral, tudo dependeu do ano realizado, dos temas abordados, das situações políticas, tecnológicas, históricas, do nível dos estudantes, das opções do grupo. E cada procedimento pedagógico nas oficinas levou a utilização de dispositivos pedagógicos diferentes. Com a realização das oficinas, ficou claro também que a EA não permite ser tratada enquanto disciplina isolada, mas necessita de tratamento interdisciplinar, e uma cumplicidade / solidariedade na construção do conhecimento a partir da interação professor-aluno.

\section{Considerações finais}

O advento da evolução científica e tecnológica somados à capacidade humana de degradar o meio ambiente põe em xeque o futuro da vida na Terra. Geólogos consideram ser necessário criar uma nova época na escala de tempo geológico para caracterizar os impactos do ser humano na Terra, considerando que em um espaço curto de vida sobre a Terra o ser humano conseguiu deixar marcas permanentes. Embora muitos dos impactos não possam ser remediados, outros tantos podem ser mitigados e prevenidos, e aqui se encontram a EA e a CTSA. Enquanto temas transversais e interdisciplinares, a EA e a CTSA são peças-chave na construção de sociedades sustentáveis, e abordá-las em escolas e na formação de professores por meio de oficinas pedagógicas possibilita ampliar o alcance de seus domínios, pois as oficinas pedagógicas são de fácil reaplicação, onde professores podem utiliza-las em diferentes temáticas e oportunidades.

A EA tem uma relevância significativa por proporcionar momentos de reflexão a respeito das nossas "atitudes" com o meio ambiente. Ou seja, ela por meio das atividades executadas possibilita que os indivíduos tenham uma melhor compreensão das condições do ambiente em que estão inseridos. Faggionato (2003) expressa que a EA "permite que os indivíduos se engajem no enfrentamento e na resolução das problemáticas ambientais (...)”. No entanto, é importante salientarmos que este processo não ocorrerá em um curto prazo de tempo. As atividades de EA realizadas em uma escola devem ser contínuas, onde, envolva a participação de todos. As oficinas pedagógicas podem desempenhar um importante papel neste processo por facilitar a interação, a tomada de decisões conjuntas e favorecer a construção coletiva do conhecimento, criando condições para que sejam protagonistas e agentes de transformação de suas realidades. 


\section{Referências}

ASTOLFI, Jean-Pierre; DAROT, Eliane; GINSBURGER-VOGEL, Yvette; TOUSSAINT, Jacques. Pratiques de formation en didactique des sciences. Paris: De Boeck Université. 1997

ASTOLFI, Jean-Pierre; DEVELAY, Michel. A didática das ciências. Campinas: Papirus. 1996

BACHELARD, Gaston. A formação do espírito científico. Rio de Janeiro: Contraponto, 1996.

BAZZO, Walter Antonio. Ciência, Tecnologia e Sociedade: e o contexto da educação tecnológica. Florianópolis: Editora da UFSC, 1998.

BRASIL. Resolução n. 2, de 15 de junho de 2012: Estabelece as Diretrizes Curriculares Nacionais para a Educação Ambiental. Diário Oficial, Brasília, n. 116, p. 70, 2012.

BRASIL. Política Nacional de Educação Ambiental. Dispõe sobre a educação ambiental. Lei n. 9795 - 27 de abril de 1999. Brasília, 1999.

CHIAVENATO, Idalberto. Recursos Humanos. Edição compacta. 5. ed. São Paulo: Atlas. 1998.

DÍAZ, Alberto Pardo. Educação Ambiental como Projeto. 2 ed. Porto Alegre: Artmed, 2002.

FAGGIONATO, Sandra. Percepção Ambiental. Disponível em: www.educar.sc.usp.br/textos. Acessado em 15/11/2018.

FARIA, Ernesto. Dicionário escolar latino-português. Rio de Janeiro: MEC, 1962.

FREIRE, Paulo. Pedagogia da autonomia: saberes necessários à prática educativa. São Paulo: Paz e Terra, 1996.

GADOTTI, Moacir. Perspectivas atuais da educação. Porto Alegre: Artes Médicas, 2000.

GIORDAN, André, DE VECCHI, Gerard. Les origines du savoir: des concepcions des apprenants aux concepts scientifiques. Neuchatel: Delachauz \& Niestlé.1987. Traducción castellana: Los orígenes del saber. De las concepciones personales a los conceptos científicos. Sevilla: Diada. 1987.

GUNSTONE, Richard; NORTHFIELD, Jeff. Metacognition and learning to teach. International Journal of Science Education, vol.16, nº 5, 523-537. 1994

HARVEY, David. Condição pós-moderna. São Paulo: Loyola, 1993 
JOSHUA, Samuel; DUPIN, Jean-Jacques. La introduction à la didactique des sciences et des mathématiques. Paris: Presses Universitaires de France, 1993.

PAVIANI, Neires Maria Soldatelli; FONTANA, Niura Maria. Oficinas pedagógicas: relato de uma experiência. Conjectura: Filosofia e Educação, Caxias do Sul, v. 14, n. 2, p.77-88, 2009. Disponível em: <http://www.ucs.br/etc/revistas/index.php/conjectura/article/view/16/15>. Acesso em: 01 nov. 2018.

PERRENOUD, Philippe. Dez novas competências para ensinar. Artmed, 2000.

PINHEIRO, Nilcéia Aparecida Maciel; SILVEIRA, Rosemari Mnteiro Castilho Foggiatto; BAZZO, Walter Antônio. Ciência, Tecnologia e Sociedade: a relevância do enfoque CTS para o contex to do Ensino Médio. Ciência.e Educação. Bauru , v. 13, n. 1, p. 71-84. 2007.

REAL ACADEMIA ESPAÑOLA (Espanha). Diccionario de la lengua española: Edición del Tricentenario. 2016. Disponível em: <http://dle.rae.es/?id=ZJ2KRZZ>. Acesso em: 02 out. 2018.

SAUVÉ, Lucie. Uma cartografia das correntes em educação ambiental. In: SATO, Michèle; CARVALHO, Isabel. Educação ambiental: pesquisa e desafios. Porto Alegre: Artmed, 2005. p. 17-44.

SCCUD. A História da SCCUD: Objetivos. 2009. Disponível em:

<http://unifespsccud.wix.com/sccud>. Acesso em: 1 outubro. 2016.

UNESCO. Educação para Todos: o Compromisso de Dakar. Brasília. UNESCO, 2001.

UNESCO. Declaração De Bonn. In: Década da Educação para o Desenvolvimento Sustentável. UNESCO, 2014.

VARGAS, Milton. Prefácio. In: GRINSPUN, Mírian P. S. Zippin.(org.). Educação Tecnológica: Desafios e Perspectivas. São Paulo: Cortez. 2011. p. 7-23.

VIEIRA, Elaine; VOLQUIND, Lea. Oficinas de ensino: O quê? Por quê? Como? 4. ed. Porto Alegre: Edipucrs, 2002. 